\title{
A MENSAGEM COMO UM SISTEMA DE REGISTROS ORGANIZADO POR REPRESENTAÇÕES QUE PROVOCAM RESPOSTAS AO ENSINO DE GEOGRAFIA
}

\author{
THE MESSAGE AS A RECORD’S SYSTEM ORGANIZED \\ BY REPRESENTATIONS THAT CAUSE RESPONSES \\ INTO GEOGRAPHY TEACHING
}

\section{LA MESSAGE COMME UNE SYSTÈME D’ENREGISTREMENT ORGANISÉ PAR DES REPRÉSENTATIONS QUI PROVOQUENT RÉPONSES DANS L'ENSEIGNEMENT DE LA GÉOGRAPHIE}

\author{
Ricardo Lopes Fonseca - Universidade Estadual de Londrina - Londrina - Paraná - Brasil \\ ricardolopesfonseca@hotmail.com
}

\begin{abstract}
Rosana Figueiredo Salvi - Universidade Estadual de Londrina - Londrina - Paraná - Brasil ro06salvi@gmail.com
\end{abstract}

\begin{abstract}
Resumo
A pesquisa teve como objetivo discutir os sistemas semióticos e seus registros de representação no ensino. Para tal, levou-se em consideração os estudos de Raymond Duval (2012) no desenvolvimento de um curso de formação continuada aplicado para 44 professores da Educação Básica. A pergunta-chave da pesquisa foi: há perda de referência no uso e reconhecimento de objetos de ensino e de seus registros de representação? As atividades de identificação, tratamento e conversão de registros semióticos foram aplicadas em nove grupos de docentes. As dificuldades manifestadas nos grupos de trabalho dos professores em formação foram: diversidade dos registros semióticos apresentados; diferenciação entre representante e representado ou forma e conteúdo de uma representação semiótica e coordenação entre os diferentes registros. Concluiu-se que não houve perda de referência entre objetos de ensino e seus registros, contudo, quando se põe em evidência a produção de mensagens e a geração de sentido e de construção de campos de significação, a resposta dos interpretantes a um texto, uma gravura, um desenho, uma fórmula, possivelmente se transforma em um outro texto, outro desenho, outra fórmula, como também pode vir a ser um outro sistema de representação, dado que se trata de significação.
\end{abstract}

Palavras-chave: Sistemas semióticos. Registros de representação. Tratamento. Conversão. Ensino.

\section{Abstract}

The research aims to discuss the semiotic systems and their representation records into geography teaching. The study was bases in Raymond Duval (2012) contributions, and it was developed in continuous training course applied to 44 basic education teachers. It were applied identification activities, semiotic records treatment, and semiotic records conversion, for nine teachers groups. The key question was: is there loss of reference in the use and recognition of teaching objects and their records of representation? The difficulties manifested for teachers groups were: diversity of semiotic records; differentiation between representative and represented or form and content of a semiotic representation, and coordination between different registers. It was concluded that there was no loss of reference between teaching objects and their records. However, the messages production and the meaning generation of construction happened the meaning fields, the response to a text, an engraving, a drawing, a formula, possibly becomes another text, drawing, and formula. The responses can be a different system of representation with another meaning.

Keywords: Semiotic systems. Representation records. Treatment. Conversion. Teaching. 


\section{Resume}

La recherche discutes des systèmes sémiotiques et de leurs enregistrements de représentation dans l'enseignement de la géographie. L'étude a été basée dans les contributions de Raymond Duval (2012), et il a été développée dans un cours de formation continue appliqué à 44 professeurs de l'école élémentaire. Ce sont les activités d'identification appliquées, le traitement des notices sémiotiques et la conversion des notices sémiotiques pour neuf groupes d'enseignants.La clé-question était: Est-ce que il y a perte de référence dans l'utilisation et la reconnaissance des objets d'enseignement et de leurs registres de représentation? Les difficultés manifestées pour les groupes de professeures ont été: la diversité des enregistrements sémiotiques; différenciation entre représentation et représentation ou forme et contenu d'une représentation sémiotique, et coordination entre différents registres. Nous avons conclu qu'il n'y avait pas de perte de référence entre les objets d'enseignement et leurs enregistrements. Mais, la production de messages et la génération de significations de construction ont eu lieu les champs de sens, la réponse à un texte, une gravure, un dessin, une formule, devient éventuellement un autre texte, dessin et formule. Les réponses peuvent être un système de représentation différent avec un autre sens.

Mots clés: Systèmes sémiotiques. Enregistrements de représentation. Traitemen. Conversion. Enseignement.

\section{Introdução}

O estudo dos signos e das significações é a essência da investigação semiótica e ocupa parte das preocupações das ciências humanas, dada a noção de que os seres humanos são produtores por excelência de sentido e de comunicação.

Na tentativa de uma aproximação entre estudos semióticos, comunicação e produção de sentidos em atividades de ensino de Geografia, tem-se como objetivo analisar os dados de uma pesquisa empírica realizada por meio de um curso de formação continuada ofertado a professores do Programa de Desenvolvimento Educacional (PDE) do estado do Paraná. Esses foram convidados a passar por uma instrução acerca dos registros de representação semiótica, realizando uma sequência de tarefas com a finalidade de julgar a pertinência do uso dos registros e o nível de dificuldade em sua compreensão.

Embora no presente artigo os dados analisados se refiram de maneira geral às atividades desenvolvidas por todos os professores, busca-se trazer reflexões para o campo do ensino de Geografia em particular. Nesse sentido, deve-se começar por entender que toda representação semiótica parte de um objeto e, nesta pesquisa, os objetos de ensino e aprendizagem foram o ponto inicial da tomada de dados.

Considera-se um objeto de aprendizagem da Geografia a partir de uma visão panorâmica de um especialista acerca de um determinado tema, consistindo de um material explanatório; aparatos para uma leitura mais aprofundada e atividades nas quais o aprendiz possa vivenciar alguma 
experiência com o assunto. Considera-se ainda que o conceito de um objeto de ensino em Geografia pode ser dinamizado na sua aprendizagem quando se realizam conversões entre registros de representação, observando que diferentes registros (textos, gráficos, mapas, tabelas) referem-se ao mesmo objeto e podem se complementar no sentido de que um registro expressa qualidades ou propriedades do objeto que não são expressas com clareza em outro registro.

Há níveis de compreensão dos tipos de signo, de objetos e de relações entre eles e interpretantes, entretanto, considerando o objetivo proposto para esta pesquisa, buscou-se apoio nas noções trazidas por Raymond Duval (2009), uma vez que ele inclui o ensino na centralidade de seus estudos semióticos.

Inicia-se o texto fazendo considerações conceituais acerca dos estudos semióticos e o ensino. Em seguida, expõe-se a metodologia, a interpretação e a análise dos dados, concluindo-se finalmente a pesquisa.

\section{Pressupostos da pesquisa}

A comunicação e a criação de sentidos se dão a partir de objetos, por meio de signos, para intérpretes. Portanto, as três primeiras noções que fixam a base dos estudos semióticos para a compreensão da comunicação são o signo, o objeto e o interpretante. Entender essa tríade implica um olhar para as representações.

Toda "representação é composta de figuras e de expressões socializadas. Uma representação [...] é a organização de imagens e linguagem porque ela realça e simboliza atos e situações que nos são ou nos tornam comuns" (Moscovici, 1978, p. 25). Para Moscovici (2003), as representações são sempre complexas e necessariamente inscritas no referencial de um pensamento preexistente.

A representação liga-se, portanto, à imagem de algo ou de alguém que a linguagem circunscreve num espaço simbólico, pois uma representação fala, mostra, comunica e exprime uma ideia, um pensamento, uma coisa. Quer dizer que a representação cria sentidos e comunica.

Representação tem sido, pois, um conceito-chave da semiótica. Pode-se dizer que a representação está para o signo e que a função do signo é a mediação. Qualquer coisa (objetos, sons, palavras) capaz de representar constitui, portanto, um signo. 
O signo é o primeiro que se coloca na criação de sentidos e na comunicação genuína. Tem relação direta com um segundo, que é o objeto representado pelo signo; e este por sua vez origina ou motiva o primeiro e é capaz de gerar ou causar um terceiro, o seu interpretante.

Um objeto para a semiótica, pode ser, portanto, uma escrita, um som, uma música, uma forma, uma cor, enfim, desde que seja algo que possa ser representado por um signo e o determine. O objeto também determina o efeito sobre seu interpretante.

Duval (1993) desenvolveu estudos acerca dos registros de representação semiótica observando que, em atividade de ensino, registros semióticos são frequentemente utilizados. Os registros semióticos são definidos como sendo "produções constituídas pelo emprego de signos pertencentes a um sistema de representações os quais têm suas dificuldades próprias de significado e funcionamento" (Duval, 1993, p. 39). Para ele, as representações consistem em um conjunto de imagens e concepções acerca de um objeto, uma situação ou algo associado a esses, tendo considerado esse conjunto como "sistemas de representações" cujos registros permitem atividades cognitivas. Um sistema semiótico pode ser, portanto, um registro de representação, desde que permita três atividades cognitivas fundamentais: formação de uma representação identificável, tratamento e conversão entre registros (Félix, 2014).

Quadro 1 - Tipos de Registros de Representação

\begin{tabular}{|c|c|c|}
\hline Registro/Representação & Representação Discursiva & $\begin{array}{l}\text { Representação não } \\
\text { discursiva }\end{array}$ \\
\hline $\begin{array}{l}\text { Registros multifuncionais ou } \\
\text { plurifuncionais } \\
\text { (não são algoritimizáveis) }\end{array}$ & $\begin{array}{l}\text { Língua natural } \\
\text { Associações verbais (conceituais); } \\
\text { Formas de raciocinar; } \\
\text { Argumentação a partir de observações, } \\
\text { de crenças; } \\
\text { Dedução partir de definição ou de } \\
\text { teoremas. }\end{array}$ & $\begin{array}{l}\text { Figuras geométricas planas ou } \\
\text { em perspectiva } \\
\text { Apreensão operatória e não } \\
\text { somente perceptiva; } \\
\text { Construção com instrumentos. }\end{array}$ \\
\hline $\begin{array}{l}\text { Registros monofuncionais } \\
\text { (possuem algoritmos próprios em sua } \\
\text { estrutura) }\end{array}$ & $\begin{array}{l}\text { Sistemas de escritas } \\
\text { Numéricas; } \\
\text { Algébricas; } \\
\text { Simbólicas. }\end{array}$ & $\begin{array}{l}\text { Gráficos cartesianos } \\
\text { Mudanças de sistemas de } \\
\text { coordenadas; } \\
\text { Interpolação; extrapolação. }\end{array}$ \\
\hline
\end{tabular}

Fonte: Adaptado de Duval (2003, p. 14). 
Os registros de representação multifuncionais ou plurifuncionais se fazem presentes nas diversas áreas do conhecimento e são anteriores ao aprendizado na escola, enquanto que os monofuncionais são formais, especializados e aprendidos a partir da escolarização.

O registro de representação da linguagem natural faz uso da forma natural dos homens se comunicarem, tal como a escrita de uma situação problema, extraída de um livro didático em que o registro de linguagem natural apareceu no enunciado da questão e o aprendiz precisa ler e interpretar o texto. O registro algébrico é a forma para se escrever leis que associam elementos e utiliza um conjunto de operações entre coeficientes numéricos e variáveis. O registro tabular é representado por linhas e colunas que formam uma tabela. O registro gráfico abrange o plano cartesiano, disposto por eixos ortogonais. Todos esses registros estão presentes nas atividades de ensino, porém, muitas vezes nem o professor e nem o aprendiz se dá conta de identificá-los e, mais ainda, não são intencionalmente utilizados na sua função de tratamento e conversão, o que fortaleceria a aprendizagem.

As atividades cognitivas relacionadas aos registros de representação são explicadas a seguir.

\section{Formação de um registro de representação - relaciona-se com a identificação do objeto representado}

A formação de uma representação identificável como um registro pode corresponder a um "enunciado de uma frase (compreensível numa língua natural dada), composição de um texto, desenho de uma figura geométrica, elaboração de um esquema, escrita de uma fórmula, [...]”. (Duval, 1993, p. 41), desde que a identificação se estabeleça por um enunciado que assegure possibilidade de tratamento.

As regras de formação de um registro de representação podem ser exemplificadas: regras gramaticais para a composição de um texto, regras de construção de tabelas para a demonstração de dados numéricos, regras para a escrita da numeração decimal etc. Essas regras são fundamentais para a construção de operações de identificação e reconhecimento de objetos. Elas permitem o contato com noções e normas de construção de gráficos e tabelas; estabelecimento de noções de distância, escala e legenda para a leitura e interpretação de mapas, associações entre ideias correlatas transmitidas em mensagens fotográficas, etc. 
Transformação de um registro de representação semiótico no mesmo sistema de representação em que foi formado - relaciona-se ao tratamento das informações entre registros

Para o ensino, o conjunto de conhecimentos postos em prática, na maior parte das vezes, é divulgado em manuais de ensino e de aprendizagem nos quais se encontram diferentes registros de representação. $\mathrm{O}$ tratamento é uma atividade de transformação de registros semióticos a partir de regras próprias cuja natureza e números variam consideravelmente.

Não se pode exigir, por exemplo, leitura e compreensão de mapas, utilizando tabelas e gráficos para isso. O mesmo se pode dizer com relação às atividades de interpretação de textos: não se pode operá-las tão somente com o uso de fotografias ou desenhos; é necessário conhecer a escrita e saber fazer a leitura de textos que expliquem relações acerca do conteúdo tratado.

Como o tratamento está subordinado a um sistema de representação específico pede um procedimento técnico, o que traz o perigo de se entender a forma como única responsável pela descrição de uma informação, uma vez que se está preso às regras de cognição do sistema em que a representação foi gerada (Duval, 2009, p. 43). Para não assinalar uma demasiada importância à forma, o tratamento não deve ser o único processo de ensino nas representações. Mapas não são tabelas e possuem regras acerca de escalas, cores e outras convenções que precisam ser respeitadas, porém podem ser utilizados em conjunto com tabelas e gráficos. O tratamento é um treinamento com objetivo de aperfeiçoar leituras e interpretações acerca dos signos.

Tarefas baseadas no tratamento remetem à ideia que Robert (1997) designa como sendo uma abordagem de nível técnico e representa, segundo a pesquisadora, um dos níveis de conhecimento em que se espera dos educandos uma utilização concreta relacionada a uma ferramenta, à aplicação de uma fórmula ou um teorema etc. Dessa forma, no tratamento são desnecessárias adaptações ou mobilização de novos conteúdos.

Transformação de um registro de representação pertencente a um sistema semiótico em outro registro pertencente a outro sistema semiótico - relaciona-se à operação de conversão entre registros

A conversão é uma atividade que permite iniciar processos de interpretação de mensagens contidas em diferentes registros ou sistemas semióticos. 
O conceito de objeto dinamiza-se quando ocorrem conversões de um registro semiótico para outro, observando que diferentes registros - gráficos, tabelas, textos, mapas, desenhos etc. - referem-se ao mesmo objeto e podem se complementar no sentido de que um registro expressa qualidades ou propriedades do objeto que não são claros em outro registro.

Essa operação é utilizada em transformações de registros que ocorrem quando há mudança de sistema semiótico de representação em referência ao mesmo objeto representado. Converter é migrar, comparar e estabelecer relações de entendimento abstraídos de um mapa para uma tabela ou gráfico, ou mesmo para um texto escrito. A conversão é, pois, uma atividade de interpretação em outro registro. A conversão das representações, de um sistema semiótico a outro, além de compreender uma operação cognitiva, caracteriza uma mudança de forma, de estrutura ou de processo. Essa operação tem que ser privilegiada em processo de ensino e aprendizagem, pois, para a maior parte dos aprendizes a transformação entre registros não é nem evidente e nem espontânea. Assim, a conversão entre registros consiste na mudança entre o registro de partida e o de chegada, porém conservando o mesmo objeto de representação. Um exemplo seria a passagem da escrita algébrica de uma equação à sua representação gráfica.

Em processos de aprendizagem, Duval (2009) observou confusão entre os objetos e suas representações, dado o fato de que a ação pedagógica ocorre normalmente a partir das representações semióticas dos objetos, embora os objetos reais sejam o alvo da aprendizagem. Na maior parte das vezes, aprendizes lidam com representação de objetos.

Refletindo esse ponto tratado por Duval (2009), para realizar atividades que envolvem objetos de ensino, a pergunta destacada na pesquisa foi: há perda de referência no uso e no reconhecimento dos objetos e de seus registros de representação?

Segundo Duval (2009), considerando um mesmo objeto e sabendo que ele pode ser representado por diferentes registros, não se pode ter compreensão

[...] se nós não distinguimos um objeto de sua representação. É essencial jamais confundir os objetos [...] com suas representações, quer dizer, as escrituras decimais ou fracionárias, os símbolos, os gráficos, os traçados de figura [...] porque um mesmo objeto [...] pode ser dado através de representações muito diferentes (Duval, 2009, p.14). 
A existência de diferentes representações para um mesmo objeto possibilita uma melhor escolha ao que se pretende ensinar, sem que se perca a sua referência real. Com base nesse pressuposto, um curso de formação foi pensado com a finalidade de disseminar as concepções de Duval (2009) e ao mesmo tempo possibilitar um cenário de reflexão acerca dos estudos semióticos no ensino.

\section{Materiais e métodos}

Os dados foram tomados em um curso de formação continuada ofertado para 44 professores da Educação Básica, em 2016, no Programa de Desenvolvimento Educacional do Paraná (PDE). Fizeram parte professores das seguintes áreas: um de Filosofia, três de Sociologia, 18 de História e 22 de Geografia.

Os participantes tiveram acesso a diversos livros didáticos e, divididos em grupos, escolheram um desses livros. A partir desta ação, cada grupo elegeu livremente um conteúdo, preferencialmente associado à sua disciplina de formação, exceto por dois grupos (G1 e G9) com característica multidisciplinar. O conteúdo selecionado tornou-se o objeto a ser representado. Após a seleção do conteúdo (identificação do objeto representado), os participantes realizaram uma sequência de atividades relacionadas com a formação de uma representação como registro, a transformação de um registro de representação no mesmo sistema em que foi gerado e a transformação de um registro pertencente a um sistema em outro registro pertencente a outro sistema. Ou seja, os professores foram estimulados a fazerem a identificação de registros, o tratamento desses e a sua conversão. Tais atividades foram extraídas da elaboração pelos professores de um Mapa Conceitual, um Mapa Conceitual Imagético, uma produção textual e busca por imagens na internet. Cada uma dessas tarefas representou um sistema para o mesmo objeto referente. O modo como cada grupo elaborou suas atividades foi considerado um tratamento entre os diferentes registros de representação. O processo de conversão foi discutido teoricamente, no nível do enunciado de mensagens, de sua significação, transmissão, codificação e interpretação. Ao todo, foram formados nove grupos codificados em G1, G2, G3, G4, G5, G6, G7, G8 e G9. Desta forma, foi possível obter a seguinte estrutura de organização: 
Quadro 2 - Organização dos grupos de professores por área de atuação e escolha de objetos de representação

\begin{tabular}{|l|l|l|l|}
\hline Código & Área de Ensino & Quantidade de Professores no Grupo & Objeto de Representação \\
\hline G1 & $\begin{array}{l}\text { Sociologia, Filosofia, } \\
\text { História e Geografia }\end{array}$ & 5 & Liberdade em Santo Agostinho \\
\hline G2 & História & 4 & Era Vargas \\
\hline G3 & História & 5 & Civilização Romana \\
\hline G4 & Geografia & 4 & Guerra-Fria \\
\hline G5 & Geografia & 5 & Globalização \\
\hline G6 & Geografia & 6 & Problemas Ambientais \\
\hline G7 & Geografia & 4 & Regiões Brasileiras \\
\hline G8 & História & 5 & Revolução Industrial \\
\hline G9 & História e Sociologia & 6 & Egito Antigo \\
\hline
\end{tabular}

Fonte: Elaborado pelos autores (2018).

O curso constou de instrução dos conteúdos por meio de exposição teórica aos professores participantes e de uma sequência de ações que foram trabalhadas em grupo, conforme sintetizadas no Quadro 3:

Quadro 3 - Sequência Didática do Curso

\begin{tabular}{|l|l|l|}
\hline Instrução & Conteúdo & Objetivo \\
\hline Aula teórica - $1^{\text {a }}$ Parte & Mapas Conceituais. & $\begin{array}{l}\text { Explicar o conceito de Mapa Conceitual e sua inserção } \\
\text { na Teoria de Aprendizagem Significativa e na Teoria dos } \\
\text { Registros de Representação Semiótica. }\end{array}$ \\
\hline Atividade 1 & $\begin{array}{l}\text { Definição de um Conteúdo } \\
\text { (objeto de ensino) por cada } \\
\text { grupo. }\end{array}$ & Identificar o objeto de representação. \\
\hline $\begin{array}{l}\text { Atividade 2 - Registro } \\
\text { de partida (RP) }\end{array}$ & $\begin{array}{l}\text { Elaboração de um Mapa } \\
\text { Conceitual. }\end{array}$ & $\begin{array}{l}\text { Colocar em prática o conhecimento adquirido na primeira } \\
\text { parte do curso. }\end{array}$ \\
\hline Aula teórica - 2 ${ }^{\text {a Parte }}$ & $\begin{array}{l}\text { Teoria de Registro de } \\
\text { Representação Semiótica. }\end{array}$ & $\begin{array}{l}\text { Explicar os conceitos que envolvem a Teoria de Registro } \\
\text { de Representação Semiótica: } \\
\text { Identificação do Objeto de Representação; } \\
\text { Tratamento; } \\
\text { Conversão. }\end{array}$ \\
\hline
\end{tabular}




\begin{tabular}{|l|l|l|}
\hline Atividade 3 & Mapa Conceitual Imagético & $\begin{array}{l}\text { Colocar em prática o conhecimento adquirido na } \\
\text { segunda parte do curso. Realizar o tratamento entre } \\
\text { registros de representação. }\end{array}$ \\
\hline Atividade 4 & Produção Textual & $\begin{array}{l}\text { Realizar tratamento e conversão entre diferentes } \\
\text { sistemas de representação. }\end{array}$ \\
\hline $\begin{array}{l}\text { Atividade } 5 \\
\text { Registro de chegada } \\
\text { (RC) }\end{array}$ & Busca por imagens na internet. & $\begin{array}{l}\text { Realizar tratamento e conversão entre diferentes } \\
\text { sistemas de representação. }\end{array}$ \\
\hline
\end{tabular}

Fonte: Elaborado pelos autores (2018).

A análise das atividades foi conduzida por dois objetivos, a saber: 1) Identificação dos sistemas de representação pelos professores em formação; 2) Transformação dos registros de representação semiótica por meio de tratamento e conversão.

Portanto, a organização das informações deu-se a partir do primeiro movimento que foi separar, em cada grupo de trabalho, os objetos selecionados pelos professores e os signos a eles relacionados para identificar os sistemas semióticos nos quais os registros foram formados (Quadro 4). Nessa etapa, agruparam-se os conjuntos de objetos e seus respectivos registros de representação selecionados pelos nove grupos. A atividade procurou proporcionar discussões e exercícios de reconhecimento do objeto selecionado em cada uma de suas representações.

Quadro 4 - Exemplos dos objetos e signos selecionados por dois grupos de professores

\begin{tabular}{|l|l|l|l|l|}
\hline Cód. & Objeto & Signo 1 & Signo 2 \\
\hline G1 & $\begin{array}{l}\text { Lonceito de } \\
\text { Liberdade } \\
\text { em Santo } \\
\text { Agostinho }\end{array}$ & &
\end{tabular}

(continua) 


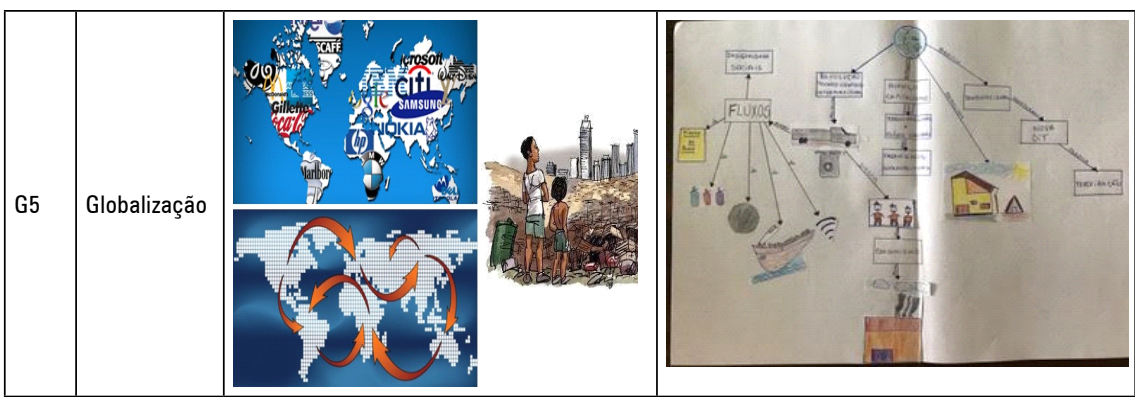

Fonte: Elaborado pelos autores (2018).

Assim procedendo, os sistemas semióticos de representação emergiram mostrando que as atividades realizadas pelos professores conduziam à próxima etapa, a de tratamento entre registros num mesmo sistema em que foram gerados e conversão entre os registros em diferentes sistemas de representação. Essa etapa procurou chamar a atenção e exercitar a coordenação de muitos registros de representação semiótica que aparecem em atividades de ensino e de aprendizagem.

Quadro 5 - Operações de tratamento e conversão entre registros semióticos de representação

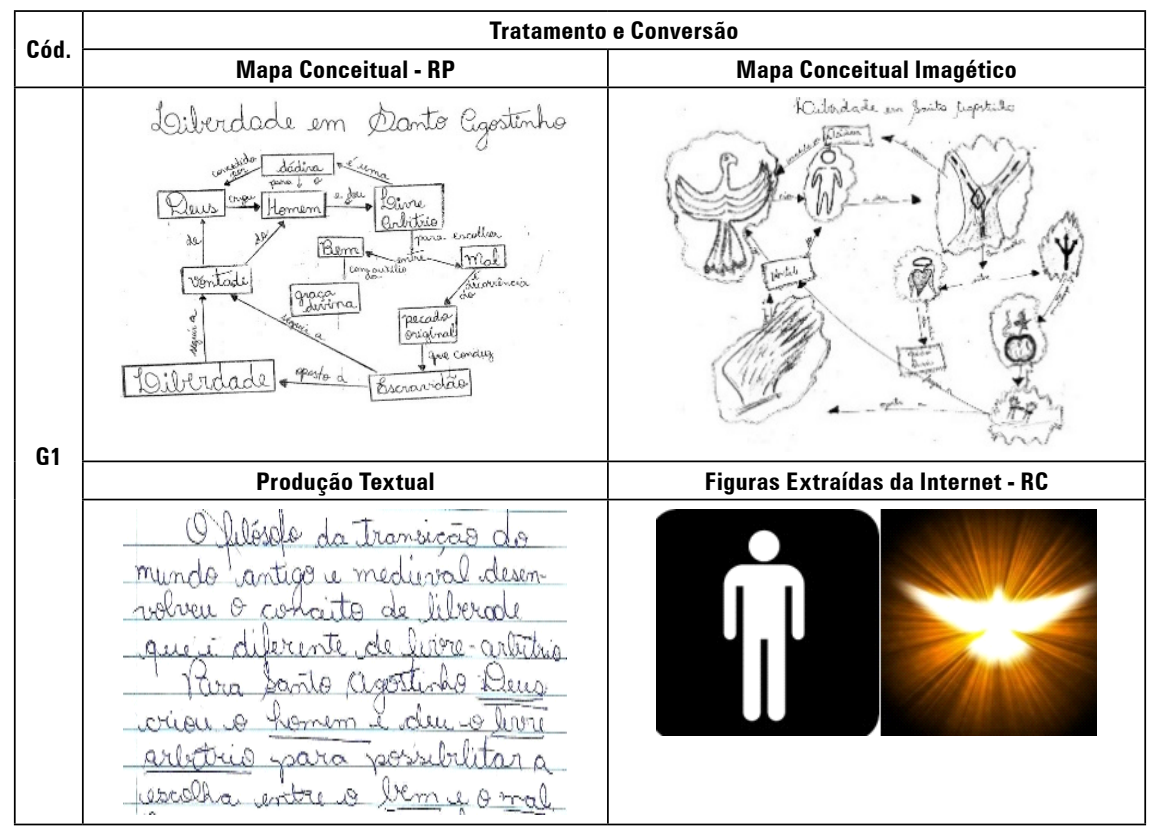




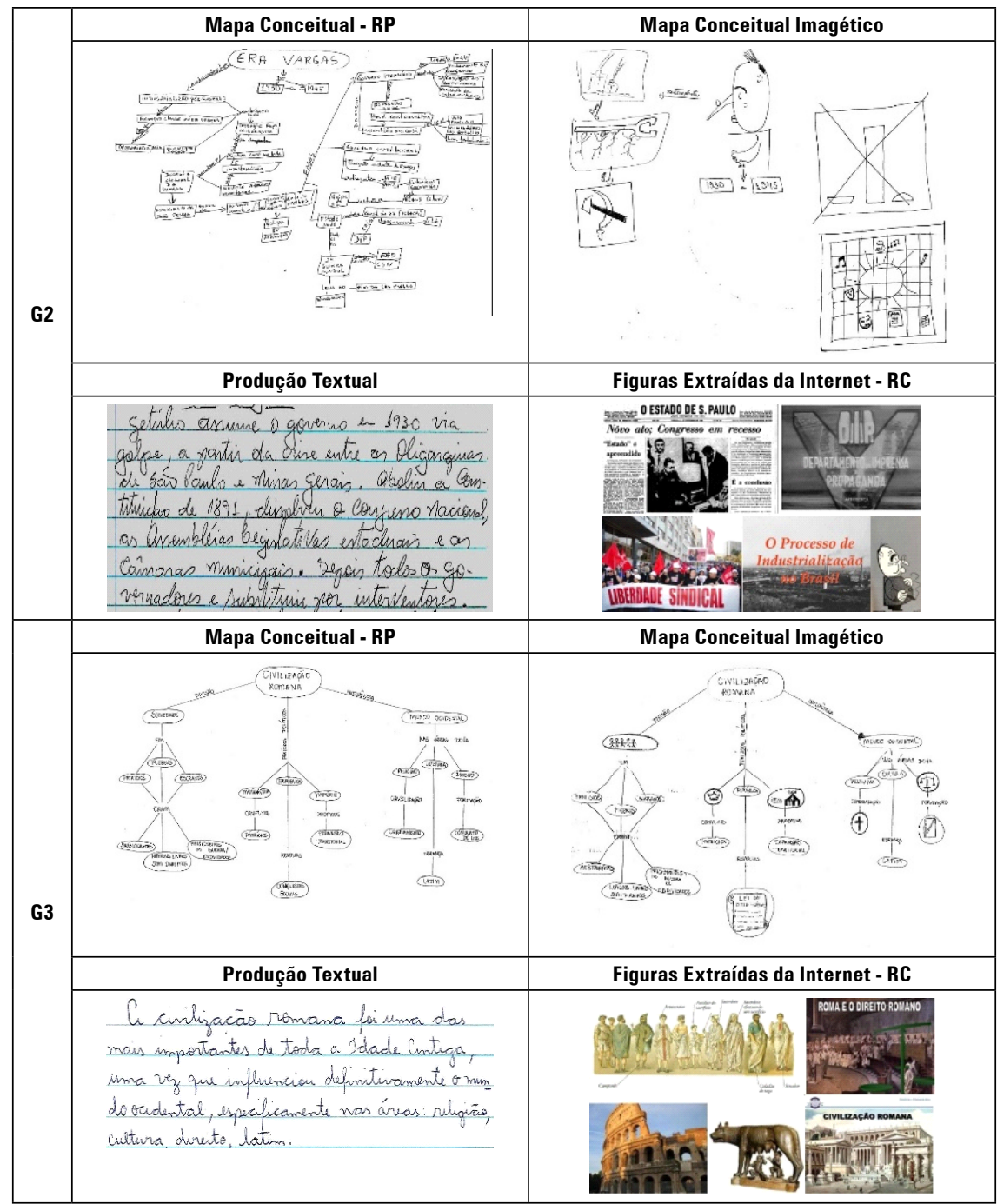

(continua) 


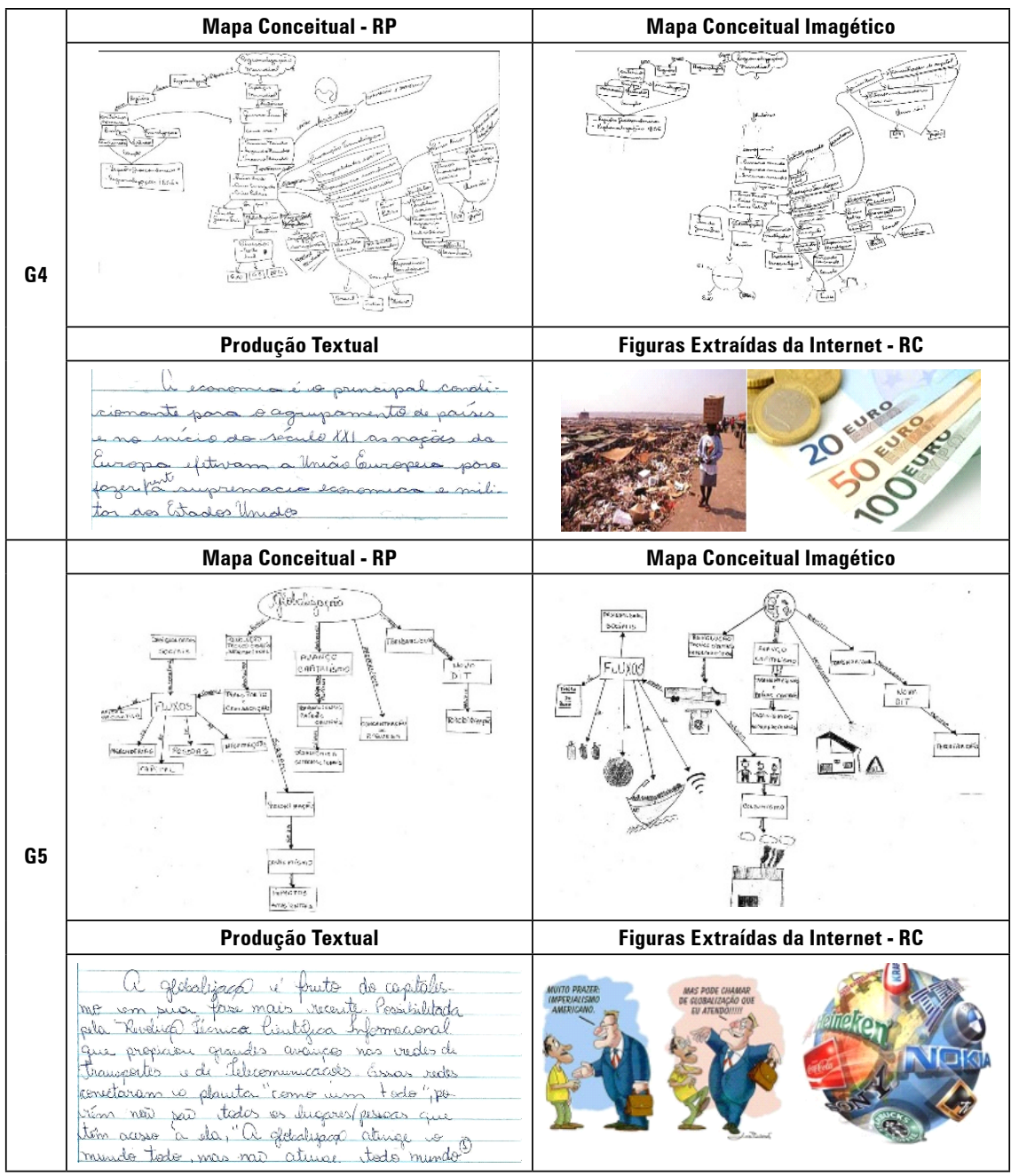

(continua) 


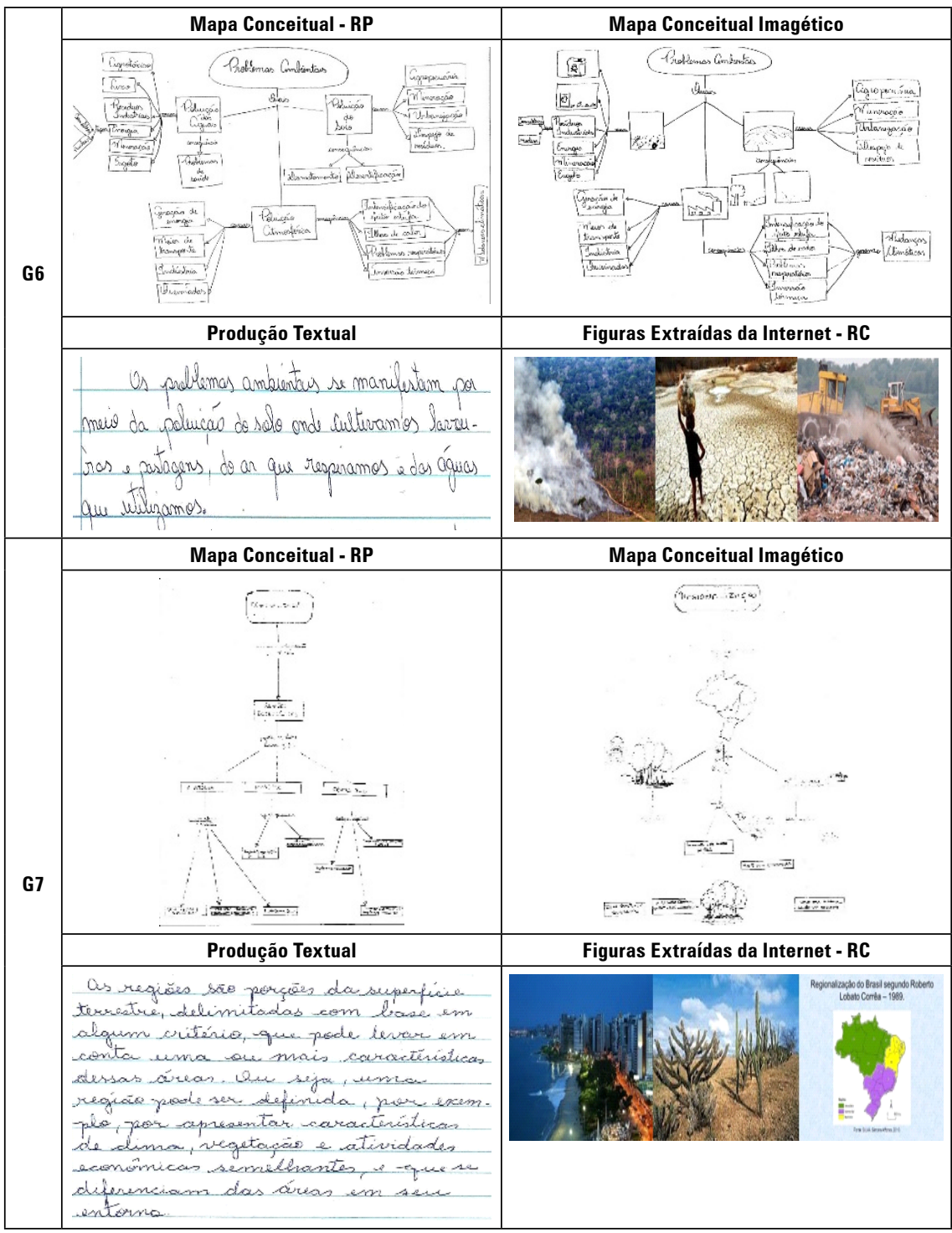

(continua) 


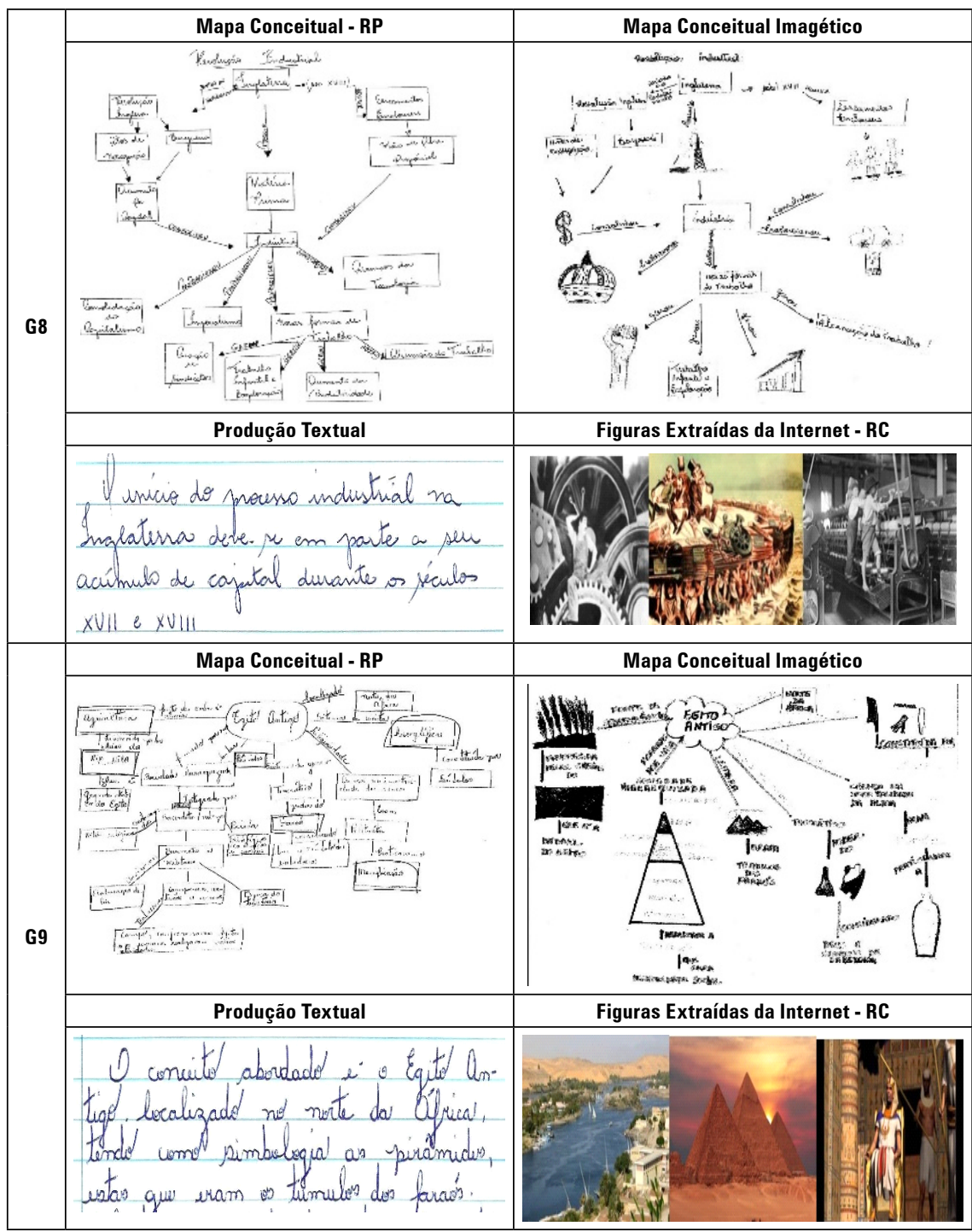

Fonte: Elaborado pelos autores (2018).

O tratamento dos registros deu-se por meio de elaboração de frases, escrita de textos, seleção de imagens, gravuras e deseñntinual que estabelecessem unidades de significação entre as representações 
escolhidas, seu objeto e seus intérpretes. Já a conversão partiu dos mapas conceituais que possibilitaram o tratamento dos registros de representação de maneira textual e simbólica, sendo as unidades de significação frases, desenhos, índices e números (Quadro 6).

Quadro 6 - Exemplo de tratamento e de conversão de um mesmo objeto de ensino

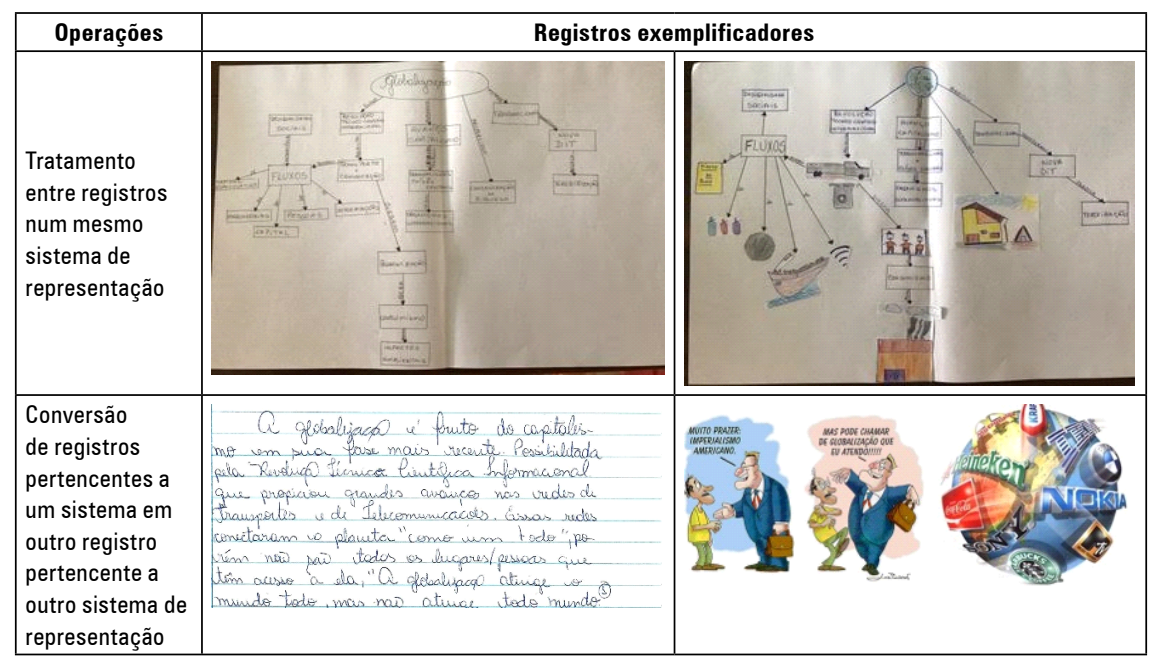

Fonte: Elaborado pelos autores (2018).

Os registros de chegada foram as imagens buscadas na internet. Estas expressaram simbólica ou discursivamente mensagens acerca das representações selecionadas e dos registros produzidos.

Fundamentalmente, buscou-se a apreensão conceitual dos objetos tentando não confundi-los com suas representações, mas ao mesmo tempo os professores procuravam extrair, discutir e analisar o reconhecimento desses objetos em suas possíveis representações. Essa foi a atividade de tratamento e conversão dos registros. É nessas duas condições que uma representação funciona verdadeiramente como representação, quer dizer, ela dá acesso ao objeto representado (Duval, 2012, p. 270).

\section{Resultado e discussão}

O primeiro aspecto levado em consideração no processo de análise dos dados foram os tipos de registros de representação que apareceram. 
Observou-se o caráter discursivo ou não discursivo dos registros mobilizados pelos professores, ao mesmo tempo em que se evidenciou a sua natureza multifuncional ou monofuncional. Esse procedimento foi realizado com o intuito de caracterizar e categorizar os registros, a fim de inferir possíveis respostas ao problema da pesquisa.

Quadro 7 - Registros de Representação apresentados pelos participantes

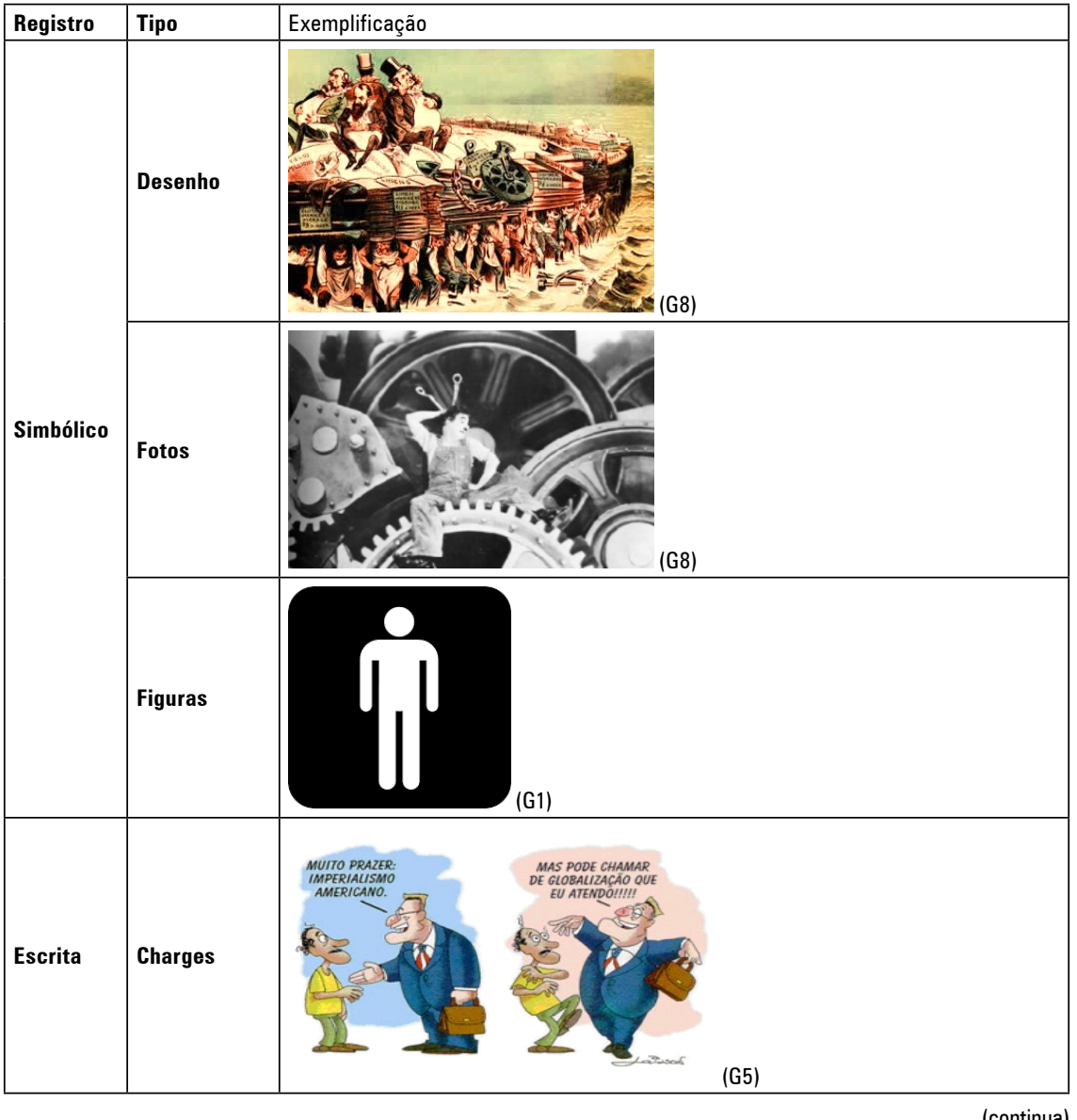




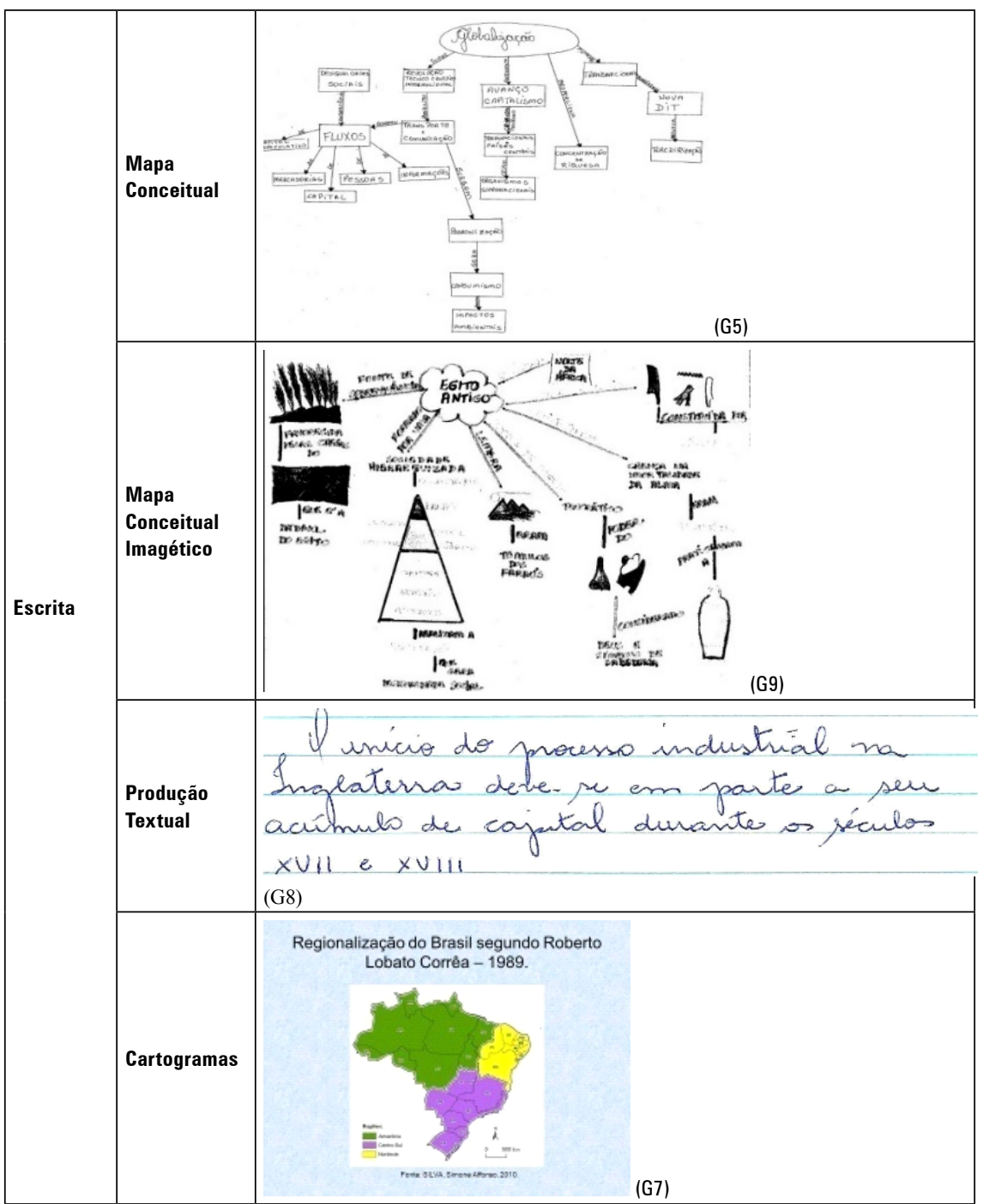

Fonte: Elaborado pelos autores (2018).

Notou-se que os grupos usaram registros multifuncionais, prevalecendo nos registros discursivos a língua natural com argumentações em torno de crenças e ideologias políticas. 
Nos registros não discursivos, sobressaiu a seleção de figuras, fotos e desenhos com alto teor simbólico. Todavia, a maior parte dos registros foram monofuncionais, prevalecendo registros discursivos simbólicos no sistema de escrita, tais como charge e artigos de jornal. Os registros não simbólicos equivaleram a mapas, fotografias de hieróglifos, esquemas e figuras.

Quadro 8 - Registros de Representação apresentados pelos participantes

\begin{tabular}{|c|c|c|c|}
\hline Registro & Representação & Tipo & Frequência Relativa (\%) \\
\hline \multirow{3}{*}{ Simbólico } & \multirow{3}{*}{ Não discursiva } & Desenho & $11 \%$ \\
\hline & & Fotos & $31 \%$ \\
\hline & & Figuras & $13 \%$ \\
\hline \multirow{5}{*}{ Escrita } & Não discursiva & Charges & $1 \%$ \\
\hline & \multirow{3}{*}{ Discursiva } & Mapa Conceitual & $13 \%$ \\
\hline & & Mapa Conceitual Imagético & $13 \%$ \\
\hline & & Produção Textual & $13 \%$ \\
\hline & Não discursiva & Cartogramas & $5 \%$ \\
\hline
\end{tabular}

Fonte: Elaborado pelos autores (2018).

Os registros simbólicos representaram 56\% do total apresentado pelos cursistas, enquanto os registros escritos somam 44\%. Os registros fotográficos compuseram a maior quantidade de representações, ao todo foram 23 registros fotográficos apresentados pelos cursistas, enquanto os desenhos foram representados oito vezes e as figuras, nove.

A variedade de representações realizadas para os outros registros (desenho, fotos, figuras, charges e cartogramas) se deu pelo fato de que os cursistas puderam escolher livremente os objetos e a forma de tratamento e conversão entre os registros.

Por outro lado, os registros de linguagem natural foram essenciais à comunicação e, assim, as regras da situação em que apareceram enunciados conduziram os grupos na leitura e interpretação dos textos. Mais do que isso, houve uma sensação agradável na discussão das problemáticas evidenciadas pelos professores. O registro algébrico, por sua vez, não foi uma forma privilegiada pelos grupos. Considerou-se a ocorrência de maneira natural, uma vez que o campo primordial de conhecimento estava concentrado nas humanidades. Sendo assim, os professores não se interessaram por descrever leis associadas aos elementos de coeficientes numéricos e variáveis. O registro gráfico 
no plano cartesiano foi um registro de representação importante para professores de Geografia, enquanto que textos escritos foram preferidos pelos professores de Sociologia, História e Filosofia. Desta forma, no que diz respeito à conversão, foi observada correspondência semântica entre as unidades significantes e uma ordem de apreensão destas nos registros de partida e chegada.

As dificuldades apresentadas pelos professores relacionaram-se a três situações específicas: 1) diversificação dos registros de representação semiótica; 2) diferenciação da forma e conteúdo de uma representação para outra; 3) coordenação entre os diferentes registros.

A primeira situação está ligada às especificidades dos diferentes registros de representação utilizados, tais como as figuras, fotos, desenhos, charges e mapas relacionados aos temas ou objetos de ensino trabalhados pelos grupos. Quando um grupo era homogêneo por área de conhecimento, tal dificuldade parecia ser menor, uma vez que a diversidade não dificultava esclarecer os tipos de registros e suas diferentes representações.

A segunda está relacionada à compreensão dos professores do que os registros representaram e, ainda, à possibilidade de associá-los a outros registros, integrando-os aos procedimentos de tratamento. Tal dificuldade foi expressiva quando se considerou a falta de prática no manuseio intencional dos registros de representação semióticos em atividades de ensino.

A terceira exigiu o preenchimento de duas condições: a utilização de dois registros diferentes para representar uma mesma situação e a conversão espontânea de um registro a outro. Essa dificuldade foi premente em todos os grupos, dado talvez a uma incompreensão acerca das possíveis conversões entre registros a partir de diferentes sistemas de representação. Novamente acentua-se a necessidade de aprimorar práticas no uso dos registros.

Acredita-se que as dificuldades mencionadas podem ser superadas na medida em que se intensifique o uso intencional das representações semióticas no ensino.

\section{Considerações finais}

As representações semióticas apresentadas pelos grupos de professores encontram-se intimamente ligadas à produção do conhecimento 
específico ao qual disciplinarmente foram formados. Por outro lado, uma vez que possibilitaram o entendimento de um objeto visto de formas diferentes, puderam ser explicitados por mais de um tipo de representação. A partir dessas representações buscou-se observar se houve perda de referência dos objetos e de seus registros de representação. Concluiu-se que, concentrados em exercícios semióticos, os professores não confundiram os objetos de ensino com as suas representações. Todavia, frente às atividades de identificação e tratamento, evidenciou-se o uso abundante de registros plurifuncionais com representações não discursivas, o que leva a inferir a necessidade de práticas que conduzam a uma maior habilidade por parte do professor em lidar com os registros, desde operações de identificação (Registro de Partida - RP) até aquelas de conversão entre registros em diferentes sistemas de representação (Registros de Chegada - RC). Acredita-se que cursos de formação possam auxiliar nessa função, intensificando a prática do uso propositado de registros de representações voltados para o ensino. Registros multifuncionais ou plurifuncionais, embora se façam presentes nas diversas áreas do conhecimento, por serem menos elaborados formalmente e menos especializados, servem bem como registros de partida, mas no processo de conversão, os registros monofuncionais desempenham papel fundamental no aperfeiçoamento do ensino e da aprendizagem.

Refletiu-se ao final acerca das condições que possibilitam afirmar que os professores foram capazes de diferenciar o conteúdo/objeto de sua representação. Observou-se que em atividades atentas para tal objetivo a tarefa pode ser facilmente desenvolvida, embora a separação entre o objeto de ensino e a sua representação, em termos de significação, basicamente inexistam. O importante, portanto, foi trazer elucidação acerca desse ponto.

Concluiu-se também que, em se tratando de pesquisas de formação docente, deve-se partir daquilo que a semiótica tem de singular: a focalização das instâncias de comunicação como lugar de produção de mensagem, de transformação da informação em signo; de geração e circulação de sentido e de construção de campos de significação.

A compreensão da interatividade dialógica entre códigos, discursos e linguagens que ocorre em instâncias da enunciação consiste, considerando as conclusões desta pesquisa, num estudo semiótico no ensino. Estamos por aperfeiçoar essas noções, pois a compreensão dessa interatividade não foi analisada. 
A abordagem deste artigo operou com a noção de mensagem como um sistema suscetível a codificações, ou seja, um sistema organizado por representações e seus registros que correspondem a signos postos em circulação e que provocam respostas para o ensino e para a aprendizagem. A abordagem assim concebida pressupôs uma codificação comum entre a emissão e a recepção dessas mensagens. A interação dialógica deve, pois, no futuro, ser melhor apreendida.

Conclui-se finalmente que, essa abordagem, ao buscar compreender atividades cognitivas relacionadas aos sistemas semióticos e seus registros de representação, não prescinde da noção de signo como algo que está no lugar de algo para alguém; logo, não pode prescindir do interpretante ou do intérprete. A resposta a um texto, a uma gravura, a um desenho, a uma fórmula transforma-se em outro texto, outro desenho, outra fórmula, como também pode vir a ser outro sistema de representação, uma vez que trata de significação. Neste caso, busca-se cada vez mais trabalhar num nível de codificação-decodificação-recodificação como atividade processual dialógica para o ensino e a aprendizagem de disciplinas curriculares, envolvendo a comunicação de mensagens e sentidos. Deve-se avançar nessas noções, mas como este estudo é ainda inicial, considerações menos preliminares estão a ser desenvolvidas.

\section{Referências}

DUVAL, R. Registre de représentation sémiotique et fonctionnement cognitif de la pensée. Annales de Didactique et Sciences Cognitives, Strasbourg, v. 5, p. 3765, 1993.

Registros de representação semiótica e funcionamento cognitivo da compreensão em matemática. In: MACHADO, S. D.A. (Org.). Aprendizagem em matemática: registros de representação semiótica. Campinas: Papirus, 2003. p.11-33.

Semiósis e pensamento humano: registros semióticos e aprendizagens intelectuais. Tradução Lênio Fernandes Levy e Marisa Rosâni Abreu da Silveira. São Paulo: Livraria da Física, 2009. (Fascículo I).

Registros de representação semiótica e funcionamento cognitivo do pensamento. Revemat: R. Eletr. De Edu. Mat., Florianópolis, v. 7, n. 2, p. 266297, 2012.

FELIX, A. C. M. Estudo dos registros de representação semiótica mediados por um objeto de aprendizagem. 2014. 150 f. Dissertação (Mestrado em Ensino 
de Ciências e Educação Matemática) - Universidade Estadual de Londrina, Londrina, 2014.

MOSCOVICI, S. A representação social da psicanálise. Rio de Janeiro: Zahar, 1978. Vozes, 2003.

Representações sociais: investigações em psicologia social. Petrópolis:

PARANÁ (Estado). Programa de Desenvolvimento Educacional do Paraná (PDE). Disponível em:<http://www.gestaoescolar.diaadia.pr.gov.br/modules/conteudo/ conteudo.php?conteudo=20>. Acesso em: 09 fev. 2017.

ROBERT, A. Quelques outils d'analyse épistemologique et didactique de connaissances mathématiques à enseigner au lycée et à l'université. Actes de la IX école d'étè de didactique des mathématiques. Houlgate, França, 1997.

Ricardo Lopes Fonseca - Graduado em Licenciatura em Geografia pela Universidade Estadual de Maringá. Mestre e Doutor em Geografia pela Universidade Estadual de Londrina. Professor Adjunto do Departamento de Geociências, Centro de Ciências Exatas pela mesma Universidade. (ID) https://orcid.org/0000-0002-2077-2476

Rosana Figueiredo Salvi - Graduada em Bacharelado e Licenciatura em Geografia pela Universidade Estadual Paulista Júlio de Mesquita Filho, Campus de Rio Claro. Mestra em Geografia Humana pela Universidade de São Paulo. Doutora em Geografia Humana pela mesma Universidade. É Professora Associada da Universidade Estadual de Londrina. (D) https://orcid.org/0000-0001-9475-9867

\section{Contribuições dos autores}

Todos os autores ofereceram substanciais contribuições científicas e intelectuais ao artigo. As tarefas de concepção e design do estudo, preparação e redação do manuscrito, bem como a revisão crítica foram desenvolvidas em dupla. Rosana Figueiredo Salvi ficou especialmente responsável pelo desenvolvimento teórico-conceitual e procedimentos técnicos. O autor Ricardo Lopes Fonseca, pela coleta de dados e sua interpretação e análise.

Recebido em 2 de dezembro de 2018

Aceito em 13 de janeiro de 2019

Publicado em XXX de XXXX de 2019 